University of Windsor

Scholarship at UWindsor

Mechanical, Automotive \& Materials

Department of Mechanical, Automotive \& Engineering Publications

Materials Engineering

Fall 9-18-2015

\title{
Optimal Configuration of Remanufacturing Supply Network with Return Quality Decision
}

Mohannad Radhi

Guoqing Zhang

Follow this and additional works at: https://scholar.uwindsor.ca/mechanicalengpub

Part of the Manufacturing Commons, Operational Research Commons, and the Operations and Supply Chain Management Commons

\section{Recommended Citation}

Radhi, Mohannad and Zhang, Guoqing. (2015). Optimal Configuration of Remanufacturing Supply Network with Return Quality Decision. International Journal of Production Research, 54 (5), 1487-1502. https://scholar.uwindsor.ca/mechanicalengpub/4

This Article is brought to you for free and open access by the Department of Mechanical, Automotive \& Materials Engineering at Scholarship at UWindsor. It has been accepted for inclusion in Mechanical, Automotive \& Materials Engineering Publications by an authorized administrator of Scholarship at UWindsor. For more information, please contact scholarship@uwindsor.ca. 


\title{
Optimal Configuration of Remanufacturing Supply Network with Return Quality Decision
}

\author{
Mohannad Radhi ${ }^{1}$, Guoqing Zhang ${ }^{1,2}$ \\ ${ }^{1}$ Supply Chain and Logistics Optimization Research Lab, Faculty of Engineering, \\ University of Windsor, Windsor, ON, Canada \\ ${ }^{2}$ Research Center of Management Science and Engineering \\ Nanjing University, China
}

\begin{abstract}
This research studies the configuration problem of a remanufacturing production network together with the decision for return quality thresholds, in which, the manufacturer has multiple remanufacturing facilities to satisfy different market demands. Quality of returns is stochastic, while demand for remanufactured products is either stochastic or deterministic. The problem we considered is to determine facilities to operate, minimum quality to accept into each operating facility, return quantity and demand allocation simultaneously so that the system's profit is maximized. The problem is formulated as a mixed integer nonlinear programming model. Through the use of a numerical example, the impact of quantity of returns, total spending, quality uncertainty, demand uncertainty, and transportation cost on the remanufacturing system is analyzed.
\end{abstract}

\section{Introduction}

Many manufacturing and production processes have negative impact on the environment, since they coincide with waste generation, ecosystem disruption and depletion of natural resources. The excessive waste generation and use of natural resources caused by today's manufacturing plants deprive the earth from its ability to recover and compensate. Thus, such processes are not environmentally sustainable. According to the U.S. Environmental Protection Agency (US EPA), the US, alone, generated more than 290 million scrap tires at the end of 2003. Those scrap tires form a breading ground for mosquitoes and are very combustible. If ignited, various hazardous materials are released to the air and into the soil harming both the environment and the living being. Therefore, to achieve sustainability and become greener, it is imperative to substantially reduce the rate of waste generation and use of natural resources through implementing the different recovery processes. Remanufacturing is one of those processes with which we could restore a used product to its original condition without being structurally destructive. It includes processes such as: collection, disassembly, inspection, testing, grading, cleaning, identification of parts, parts recovery and product re-assembly. 
Remanufacturing has increased drastically in the last two decades due to the increase in producer and consumers awareness regarding remanufacturing outcomes. Remanufacturing is an approach used by many companies from different industries such as Dell, Hewlett-Packard (HP), IBM, Kodak, Xerox, General Motors (GM), and Goodyear. An example of the different remanufactured products includes: photocopiers, cellular telephones, single-use cameras, car's engines and transmissions and retreaded tires.

This paper discusses a remanufacturing system in which remanufactured products have less monetary value compared to newly manufactured products (no perfect substitution). According to Akcali \& Cetinkaya (2011), literatures concerning closed loop supply chain and remanufacturing systems, in the last two decades, have heavily considered the case of perfect substitution and not the case without perfect substitution, although the second one is much more applicable in today's market if durable products are considered.

The research is also inspired by a deep relationship between quality and many remanufacturing attributes (e.g. returns' acquisition price, remanufacturing cost, remanufacturing lead time and pre-remanufacturing holding cost). Such a relationship could be found in many durable products that have a long usage period and low demand volume. In this paper the return's acquisition price vs. quality is described by an increasing function, while remanufacturing cost vs. quality is described by a decreasing function. The summation of those two costs introduces a decreasing function in terms of quality. As a result, better quality returns are always more appreciated as they are associated with lower total spending and thus more profit. Thus, if returns are thoroughly inspected and assigned quality scores or classes by the remanufacturers, then the individual return's quality in this case is uncertain. This uncertainty should be represented by an appropriate quality distribution. According to Akcali \& Cetinkaya (2011), literatures concerning remanufacturing systems and closed loop supply chains have not adequately addressed quality uncertainty.

Our first contribution is to propose the quality grading method and acceptance decision for the returned products in a remanufacturing system with uncertain quality of returns. This research studies two cases of return quality distribution: normal and exponential, and study their impact on the system's behavior.

Our second contribution is to integrate optimal configuration of supply network for a remanufacturer with return quality decision, where the remanufacturer runs multiple facilities to satisfy different market demands by remanufacturing used products. We consider both deterministic and stochastic demands. To the best of our knowledge, this is the first work that considers a remanufacturing network with return quality decision. 
The third contribution of this research is to develop mixed integer non-linear programming models to determine supply and market allocation and optimal minimum quality to accept into each operating facility so that the total profit is maximized.

The rest of this paper is organized as follows. Related literature is first reviewed in Section 2 and then mathematical models are presented in Section 3. After that, an example is solved and numerical results are reported in Section 4. Section 5 performs sensitivity analysis. Section 6 is a simple extension of the previous work. Finally, conclusion and suggested future research are presented in Section 7.

\section{Related Works}

A handful papers concerning CLSC and remanufacturing systems consider quality uncertainty or condition variability in used and returned items. Representation of condition variability through the use of defined probability density function is scarce. In Galbreth and Blackburn (2010), returns in each acquired lot are distributed uniformly over a range of conditions with certainty. The embedded uncertainty in each item's condition is, also, presented through the use of negative binomial distribution. The work minimizes total acquisition and remanufacturing costs through the use of optimal quantity acquired. Wei, Tang \& Liu (2014) argue that acquisition price paid for returns should balance between the capital tied up for customers and the risk that customers may leave the cores to another collector. They stated that pricing should, also, be appropriate such that cores with higher quality are more encouraged to be returned. In the presence of customer evaluation, three refund policies are studies: single with a sole refund for all returns, multiple with a refund for each qualitycategory, and perfect with a refund for each quality-evaluated return. Uniform and adjusted normal distributions are used to represent quality uncertainty. In Wassenhove \& Zikopoulos (2010), returns are inspected twice: first by $\mathrm{N}$-suppliers who assign a grade to each return and second by the remanufacturer who confirms credibility of this assignment. The probability of correct classification is stochastic and is considered to be a form of quality uncertainty. The paper examines the negative impact of misclassification or overestimation of returns on procurement decisions and system's profitability. Watanabe, Kusuawa \& Arizono (2013) study a hybrid system that satisfies demand from both newly manufactured items and remanufactured returns. The performance of a decentralized system, with a retailer-Stackelberg game, and a centralized system, with retailer-manufacturer cooperation, are studied and compared. The paper seeks to optimize the lower quality limit, incentive paid to customers by the retailer and quantity ordered by the retailer at the beginning of the selling period. Both Wassenhove \& Zikopoulos (2010) and Watanabe, Kusuawa \& Arizono (2013) assign beta distribution to quality uncertainty to capture a large number of different characteristics by adjusting the two shape 
parameters. Robotis, Boyaci \& Veter (2012) examine the impact of normally distributed quality on a hybrid system under product reusability and return quantity investments.

On the other hand, undefined probability density functions are used, sometimes, to model quality uncertainty (Galbreth and Blackburn 2006; Ferguson et al. 2009; Robotis et al. 2005). In Ferguson et al. (2009) returns are classified into three quality grades: scrap, harvest for parts, or fit-for-remanufacturing. In the study, returns' quantity is deterministic and demand is either stochastic or deterministic. Several costs vs. quality relationships are addressed, but acquisition price vs. quality relationship is not. The objective of the model is to maximize total profit by optimizing returns to remanufacture, to salvage, and to hold for future periods. The study presented by Robotis et al. (2005) is for an enterprise that practice both reselling and remanufacturing at the same time. The paper's objective is to compare between the performance of a system with vs. a system without remanufacturing activities. System's performance is enhanced by selecting the optimal acquired quantities, optimal remanufactured quantities and quality range of remanufactured returns.

In some other cases, quality of returns takes the form of discrete random variable (Galbreth and Blackburn 2010; Teunter \& Flapper 2011; Behret \& Korugan 2009; Aras et al. 2004). In Teunter \& Flapper (2011), quality is assigned a multinomial distribution since returns are divided into $k$ different quality types and each type has a certain probability. Sorting is performed after acquisition and the acquisition price is either fixed or quantity dependent. Due to the sequence of events, remanufacturing cost is considered to be quality dependent, while acquisition price is not. The model optimizes a newsboy-type problem by choosing the proper acquisition quantity in certain and uncertain demand environments. Also, simulation is used in Behret \& Korugan (2009) to verify the importance of quality classification. The paper compares between a system without quality classification and an alternative one with quality classification. In the study, returns are classified into either good quality, average quality or bad quality. Yield or recovery rate from each returned item, remanufacturing processing cost, remanufacturing effort, operational disposal cost, and remanufacturing overflow disposal cost are all considered to be quality dependent. Both demand and return quantity are considered to be stochastic and follow Poisson distribution. Moreover, the problem setting defined in Aras et al. (2004) is very similar to that defined in the paper presented by Behret \& Korugan (2009). They present similar cases in which quality classification is a better approach. There are few differences between the two studies such as number of quality classifications for returns and consideration of remanufacturing lead-time. The paper calculates the holding cost based on quality level. This study uses Continuous Markov Chain optimization technique to solve for the minimum long-run average system cost. 
Quality uncertainty could be addressed as the yield or the percentage of remanufactureables in a lot of returns (Bakal \& Akcali 2006; Zikopoulosa \& Tagarasa 2008; Mukhopadhyaya \& Ma 2009). When yield is used, in either its stochastic or deterministic forms, the different costs associated with remanufacturing are not quality dependent, but rather fixed. The paper Bakal \& Akcali (2006) analyses the automotive remanufacturing industry in the U.S. The objective of the paper is to maximize the firm's profit by choosing the optimal selling and acquisition prices. Return quantity, demand quantity and return quality are all assumed to be price dependent. Moreover, return and demand quantities are assumed to be deterministic, while the yield is assumed to be either deterministic or stochastic. Zikopoulosa \& Tagarasa (2008) presents a study in order to encourage the remanufacturing firms to design or develop a sorting or quality evaluation mechanism for the returns. The paper compares between the profitability of a system that has no sorting before disassembly and another with sorting before disassembly. The model optimizes system's performance by selecting optimal remanufacturing and procurement quantities when demand is behaving uncertainly. Mukhopadhyaya \& Ma (2009) maximizes system's profit through the use of optimal return quantity to take back, items to acquire or to order, and items to produce. This paper has a novel contribution for considering delivery lead-time in the case of random yield.

CLSC literature is rich with papers that do not consider quality uncertainty or variation in condition of returns. Thus, each remanufactured return is assumed to cost exactly the same irrespective to its quality. An example of such a direction is the work presented by Shi et al. (2010). They study a perfect substitution environment with manufacturing and recycling options. The study has the precedence in presenting the return quantity as a non-linear function of the acquisition price. The total expected profit is maximized by optimizing recycling quantity, manufacturing quantity, serviceable inventory stocking level as well as acquisition price. An extension of the previous work is Shi et al. (2011a) with a difference that this work is modeled by considering a linear relationship between return quantity and acquisition price. Another difference between the two works is that the return horizon is considered from the beginning of the planning period to the end of the remanufacturing period in the later study. Another extension of the earlier work is Shi et al. (2011b) with similar problem settings. The study optimizes quantities of return and demand by setting the optimal acquisition and selling prices. This paper assumes that quantities have linear relationships with their corresponding prices. Hsueh (2010) has the precedence in presenting dependency between demand and return quantity that takes into account the different phases of the product life cycle. The study assumes that both demand and return quantities follow normal distribution with a changing mean depending on the specific phase of the PLC. Closed form formulas are derived to calculate the optimal production quantity, reordering point and safety stock in each phase of the PLC. Many papers in the CLSC literature study systems with deterministic attributes such as Koh et al. (2002), Konstantaras et al. (2010) and Chiu et al. (2009). 
Several papers have addressed the issue of networking in a CLSC context. Jayaraman et al. (1999) shows that the existence of a remanufacturing facility in certain market depends on both the demand of that market (similar to a traditional SC) and the availability of returns in that market (different than a traditional SC). In this paper, we argue that the availability of returns is necessary, but not sufficient due to the fact that condition of those returns plays, also, a vital role. Ko \& Evans (2007) have proposed a heuristic MINLP model for a third party logistics provider in a CLSC. Due to the complexity of the model (NP hard), many heuristics have been developed and tested to optimize the system. A deterministic programming model was introduced by Lee \& Dong (2008) to optimize a computer products network. Due to the difficulty of the problem, a two stages heuristic is developed. Reconfigurability of the network or its ability to adjust to new operational conditions is found to be more advantageous if it does not coincides with extremely high initial investment (Listes 2007). It is noticeable that none of the previous papers nor many others in the field of CLSC networking (Salema et al. 2007; Salema et al. 2006; Bostel \& Lu 2007; Saman \& Zhang 2012) addressed quality uncertainty.

In contrast to the previous literature, this work studies the impact of quality uncertainty or condition variability on a network of remanufacturing facilities and markets. Also, this paper assumes quality to follow either normal or exponential distribution. Comparison between system's behavior and profitability with respect to each distribution is conducted.

\section{Model Formulation}

Few remanufacturing facilities perform quality grading for returns prior to purchasing or dismantling. Indeed, finding such quality grades in many industries is difficult due to the lack of knowhow, absence of technological enablers or complexity of the return's structure. Thus, choosing a proper industry is a vital step before we could formulate the problem. One of the industries that have a great potential to benefit from this study is the tires remanufacturing or retreading industry.

There are three key players in the retreading industry. As shown in Figure 1, the collectors or tire retailers collect used tires from the customers. The haulers aggregate, sort and deliver collected tires to the appropriate processors. Sorting is performed to separate retreadable from non-retreadable tires in an effort to sell those retreadable tires to a remanufacturing facility. According to Ontario Tire Stewardship (2009), retreadable tires could bring up to one third of their original price (up to $\$ 100$ ) in revenue for the Haulers. Consequently, every retreadable tire is potentially associated with high revenue. This aggregation and sorting processes are assumed

to be performed periodically. Lastly, the several processors (e.g. retreading plant) process scrap or used tires to produce useful and environmentally responsible products. 


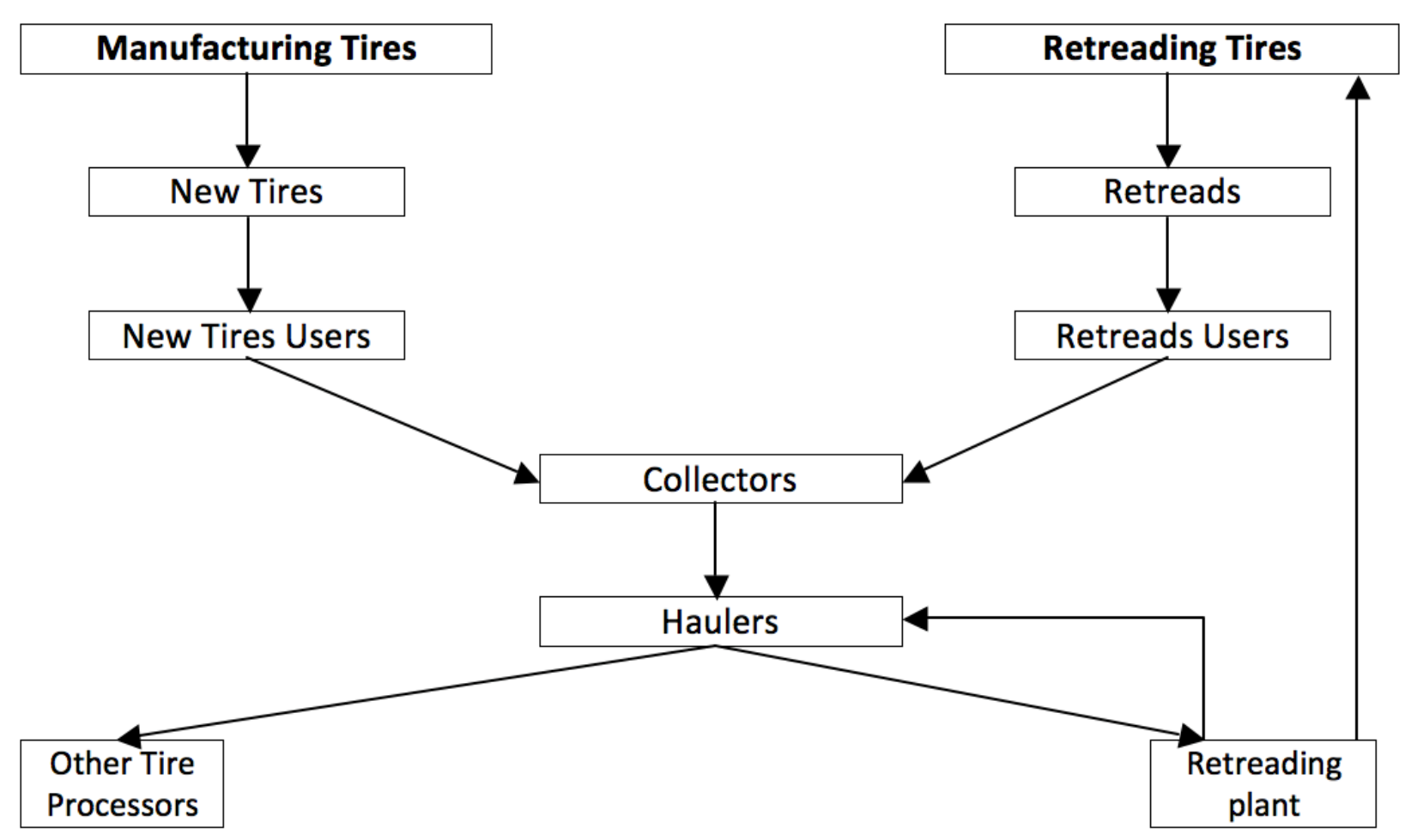

Figure 1: Tire Supply Chain

Once used tires are received by the remanufacturing facility, each tire is thoroughly inspected and graded. According to Ferguson et al. (2009), adapting quality grading prior to remanufacturing increases profitability regardless of the quality distribution. Thus, each return is given a quality score ranging from 0 to 100 . If the return has a higher quality grade than the optimal minimum quality, then it is acquired with a price that coincides with its quality and advanced to the remanufacturing process without being stored. Otherwise, it is rejected from the remanufacturing process and assigned back to the hauler. Redirecting rejected tires to another waste stream or to another processor is the responsibility of the hauler. The remanufacturing facility bears no cost associated with any rejected tire including the transportation cost, because it is the haulers responsibility to deliver the appropriate tire to the appropriate processor. The enterprise may operate a network of multiple remanufacturing facilities to satisfy the demand of multiple markets. Each facility may face different parameters and each market may have different characteristics.

With the objective of maximizing the total expected profit of the system, the enterprise needs to decide remanufacturing facility location and market allocation. At the same time, to control the product take-back, it is important to determine the optimal minimum quality of returns to accept into each operating facility. We formulate the problem as mixed integer nonlinear programming models. 


\section{Model Assumptions:}

- Inspection and quality grading processes are assumed to be very precise and the speculation of return's remanufacturing cost is always correct.

- As quality increases, both remanufacturing cost decrease and acquisition price increase linearly. The slope in each relationship is set such that it is more profitable to remanufacture higher quality returns compared to lower quality returns. The assumption that the remanufacturing cost has a negative linear relationship with the quality is addressed in several papers including: Galbreth and Blackburn (2006), Ferguson et al. (2009), Galbreth and Blackburn (2010) \& Watanabe, Kusuawa \& Arizono (2013). Also, studying a system that assigns an acquisition price for each return based on its exact quality is inline with the work done by Wei, Tang \& Liu (2014). They argue that such a refund policy is found to be better than setting a sole acquisition price for all returns or setting an acquisition price for every quality-category.

- Quality is assumed to be stochastic with either normal or exponential distribution. This assumption is based on the following facts:

- Due to economical reasons, many off the road (OTR) tires, which serve in a slow and harsh working environment, are not considered to be out of service until most of their economical value is well consumed. As a result, quality of returns spread close to the lower quality limit. Thus exponential distribution is chosen.

- Due to safety reasons, many on the road tires, which serve on cities, are considered to be out of service while they are in decent quality. Thus quality of returns spread in between quality limits (e.g. between 0 and 100). As a result, normal distribution is chosen. According to Wei, Tang \& Liu (2014), this assumption is valid especially if tires are collected from both collectors and individuals.

- Demand is assumed to be either deterministic or stochastic with normal distribution.

- Since the amount of used-tires can easily satisfy facility needs, the amount of returns $(R)$ is considered to be independent and either deterministic or a decision variable. Relatively, Watanabe, Kusuawa \& Arizono (2013) assume the amount of returns to be price-dependent. If returns have unlimited supply, this assumption works will have high remaining functional value and do not propose a threat to users.

- If $(R)$ is not a decision variable, then inspection cost is assumed to be zero.

- The system does not have a pre-remanufacturing inventory, because of two main issues. First, tires are combustible and could attract mosquitoes. Thus, they should be stored in a controlled, shaded, and dry environment. Also, they are very bulky and storing those tires requires a spacious warehouse. Thus, storing used tires could be very expensive. Moreover, 
tires deteriorate with time and there will always be new tires dumped into the system that exceed market's demand. Therefore, it is better for the facility not to include a preremanufacturing inventory system.

- The system include post-remanufacturing inventory in the case of uncertain demand as production might exceed actual demand. Therefore, over-stocking cost is introduced to the model only in the case of uncertain demand. Moreover, under-stocking cost is always considered in the models as it might be optimal not to satisfy demand even if it is predetermined.

The following notations are used in the models:

\section{Indices:}

$i \quad$ Set of facilities $(1, \ldots, F)$

$j \quad$ Set of markets $(1, \ldots, M)$

\section{Parameters:}

$U \quad$ Under-stocking Cost

$O$ Over-stocking Cost

$P \quad$ Selling price

a Acquisition price assigned for worst possible remanufacturable return

$b \quad$ Slope of acquisition price vs. quality linear relationship

$\alpha \quad$ Remanufacturing cost assigned for worst possible remanufacturable return

$\beta \quad$ Slope of remanufacturing cost vs. quality linear relationship

$R \quad$ Quantity of return assigned for facility $i$

$D_{j} \quad$ Forecasted demand for market $j$, used when demand is deterministic

$C s_{i} \quad$ Setup cost for facility $i$

$C a_{i} \quad$ Capacity limit for facility $i$

$T_{i j} \quad$ Transportation cost per item from facility $i$ to market $j$. This cost is zero if demand is satisfied from a local remanufacturing facility

$\mu_{q_{i}} \quad$ Average quality of returns delivered to facility $i$

$\sigma_{q_{i}} \quad$ Quality standard deviation, for the normal quality distribution, experienced by facility $i$

$f_{q}(.)_{i}$ PDF for the variables following the distribution assigned for quality in facility $i$

$F_{q}(.)_{i}$ CDF for the variables following the distribution assigned for quality in facility $i$

$d_{j} \quad$ Actual demand for market $j$, used when demand is stochastic

$\mu_{d_{j}} \quad$ Average demand for market $j$, used when the system is modeled with stochastic or normally distributed demand 
$\sigma_{d_{j}} \quad$ Demand standard deviation for market $j$, used when the system is modeled with stochastic or normally distributed demand

$f_{d}(.)_{j}$ PDF for the variables following the distribution assigned for demand in market $j$

$F_{d}(.)_{j}$ CDF for the variables following the distribution assigned for demand in market $j$

$a+b * q_{i} \quad$ Acquisition price vs. quality linear relationship

$\alpha-\beta * q_{i} \quad$ Remanufacturing cost vs. quality linear relationship with $\beta>b$

\section{Stochastic Variables:}

$\pi \quad$ Expected system's profit, which is the objective function to be maximized

$q_{i} \quad$ Actual quality of returned item to facility $i$

\section{Decision Variables:}

$\omega_{i} \quad$ Binary variable $(0,1): \quad 0=$ facility $i$ is not operating

$$
1=\text { facility } i \text { is operating }
$$

$Q_{i} \quad$ Optimal minimum quality to accept into facility $i$

$V_{i j} \quad$ Number of items supplied by facility $i$ to market $j$

\section{Modeling for deterministic demand (Model 1):}

If the demand on remanufactured products is certain, then the profit function should be:

$$
\begin{aligned}
\pi & =\left\{\sum_{i=1}^{F} \sum_{j=1}^{M} V_{i j} * P\right\}-\left\{\sum_{i=1}^{F} \int_{Q_{i}}^{\infty}\left[a+b * q_{i}\right] * R_{i} f_{q}\left(q_{i}\right)_{i} d q_{i}\right\} \\
& -\left\{\sum_{i=1}^{F} \int_{Q_{i}}^{\infty}\left[\alpha-\beta * q_{i}\right] * R_{i} f_{q}\left(q_{i}\right)_{i} d q_{i}\right\}-\left\{U *\left(\sum_{j=1}^{M} D_{j}-\sum_{i=1}^{F} \sum_{j=1}^{M} V_{i j}\right)\right\} \\
& -\left\{\sum_{i=1}^{F} \omega_{i} * C s_{i}\right\}-\left\{\sum_{i=1}^{F} \sum_{j=1}^{M} T_{i j} * V_{i j}\right\}
\end{aligned}
$$

Then, the problem can be formulated as (Model 1):

$\operatorname{Max} \pi$

Subject to:

$\sum_{j=1}^{M} V_{i j} \leq \int_{Q_{i}}^{\infty} R_{i} f_{q}\left(q_{i}\right)_{i} d q_{i}$ for each $i$

$\int_{Q_{i}}^{\infty} R_{i} f_{q}\left(q_{i}\right)_{i} d q_{i} \leq C a_{i} \quad$ for each $i$

$D_{j} \geq \sum_{i=1}^{F} V_{i j} \quad$ for each $j$

$Q_{i} \geq\left(1-\omega_{i}\right) * L$ for each $i$ 
$Q_{i} \leq 100 * \omega_{i}+\left(1-\omega_{i}\right) * L \quad$ for each $i$

$V_{i j} \leq \omega_{i} * R_{i} \quad$ for each $i$ and $j$

It is noted that the objective function with integration to infinite is a good approximation since the actual distribution of the quality limits the probability beyond 100 . The meaning of each term in the objective function (1) is explained next. The first term refers to the revenue generated by selling all items supplied from all facilities $i$ to all markets $j$ in the case of deterministic demand. The second and third terms refer to the overall returns' acquisition cost and remanufacturing cost experienced by the enterprise respectively. The fourth term addresses the overall under-stocking cost the enterprise is facing. Lastly, fifth and sixth terms refer to the overall setup and transportation costs respectively. With regard to the constraints, the quantity constraint (2) makes sure that facility $i$ will only satisfy demand from the quantity that have been accepted and remanufactured by the facility which is equivalent to $\int_{Q_{i}}^{\infty} R_{i} f_{q}\left(q_{i}\right)_{i} d q_{i}$. The capacity constraint (3) verifies that production from facility $i$ does not exceed the capacity limit for that facility. The demand constraint (4) forces the system not to exceed the deterministic demand from market $j$. Thus, the system experiences no over-stocking scenario in the case of deterministic demand.

The first quality constraint (5) and the second quality constraint (6) make sure that the optimal minimum quality is meaningful (i.e. $0 \leq Q_{i} \leq 100$ ) where $L$ is a very large number. Based on the constraints, if facility $i$ is operating (i.e. $\omega_{i}=1$ ), then the optimal minimum quality is $0 \leq Q_{i} \leq 100$; otherwise, if facility $i$ is not operating (i.e., $\omega_{i}=0$ ), then the optimal minimum quality $Q_{i}$ is a very big number, which means the facility does not take any return. In this case $\int_{Q_{i}}^{\infty} f_{q}\left(q_{i}\right)_{i} d q_{i} \approx 0$ for both the normal and exponential distributions, which gives a good approximation. A similar assumption is used by Robotis, Boyaci \& Veter (2012) when modeling the normally distributed remanufacturing cost.

The inequality (7) is the excess quantity correction constraint. In our model we use distributions that may have values between $-\infty$ and $+\infty$. Thus, the previous quality constraints might not be enough to block all returns from entering a non-operating facility. This is true, because we could not choose infinity instead of a very large number while programming GAMS as infinity is unrecognized value. Thus, this constraint is added to compensate for such an error if it exists. As a result, it ensures that no demand is satisfied from a non-operating facility. 


\section{Modeling for stochastic demand (Model 2):}

If the demand on remanufactured products is uncertain, then the profit function should be as:

$$
\begin{aligned}
& \pi^{\prime}=\left\{\sum_{j=1}^{M} \int_{-\infty}^{\sum_{i=1}^{F} V_{i j}} P * \mathrm{~d}_{\mathrm{j}} f_{d}\left(\mathrm{~d}_{\mathrm{j}}\right)_{j} d \mathrm{~d}_{\mathrm{j}}\right\}+\left\{\sum_{j=1}^{M} \int_{\Sigma_{i=1}^{F} V_{i j}}^{\infty} P * \sum_{i=1}^{F} V_{i j} f_{d}\left(\mathrm{~d}_{\mathrm{j}}\right)_{j} d \mathrm{~d}_{\mathrm{j}}\right\} \\
& -\left\{\sum_{i=1}^{F} \int_{Q_{i}}^{\infty}\left[a+b * q_{i}\right] * R_{i} f_{q}\left(q_{i}\right)_{i} d q_{i}\right\}-\left\{\sum_{i=1}^{F} \int_{Q_{i}}^{\infty}\left[\alpha-\beta * q_{i}\right] * R_{i} f_{q}\left(q_{i}\right)_{i} d q_{i}\right\} \\
& -\left\{\sum_{j=1}^{M} O * \int_{-\infty}^{\Sigma_{i=1}^{F} V_{i j}}\left(\sum_{i=1}^{F} V_{i j}-\mathrm{d}_{\mathrm{j}}\right) f_{d}\left(\mathrm{~d}_{\mathrm{j}}\right)_{j} d \mathrm{~d}_{\mathrm{j}}\right\} \\
& -\left\{\sum_{j=1}^{M} U * \int_{\sum_{i=1}^{F} V_{i j}}^{\infty}\left(\mathrm{d}_{\mathrm{j}}-\sum_{i=1}^{F} V_{i j}\right) f_{d}\left(\mathrm{~d}_{\mathrm{j}}\right)_{j} d \mathrm{~d}_{\mathrm{j}}\right\}-\left\{\sum_{i=1}^{F} \omega_{i} * C s_{i}\right\}-\left\{\sum_{i=1}^{F} \sum_{j=1}^{M} T_{i j} * V_{i j}\right\}
\end{aligned}
$$

Thus, the problem can be formulated as (Model 2):

$\operatorname{Max} \pi^{\prime}$

Subject to:

Constraints (2), (3), (5), (6), and (7).

In the objective function (8), the first and fifth terms are the revenue generated by the enterprise and the expected over-stocking cost respectively. They are used if the uncertain demand in market $j$ is found to be less than all remanufactured items supplied by all facilities $\sum_{i=1}^{F} V_{i j}$ to that specific market. Also, the second and sixth terms are the revenue generated by the enterprise and the expected under-stocking cost respectively. They are used if the uncertain demand in market $j$ is found to be more than all remanufactured items supplied by all facilities $\sum_{i=1}^{F} V_{i j}$ to that specific market.

\section{Numerical Example and Results}

The problem formulated above is a Mixed Integer Non-Linear Programming (MINLP). We employ GAMS to solve the example given in Table 1. 


\begin{tabular}{|c|c|c|c|c|c|c|c|}
\hline Parameter & Value & Parameter & Value & Parameter & Value & Parameter & Value \\
\hline$i \in$ & $\{\mathrm{ON}, \mathrm{QC}, \mathrm{MB}\}$ & {$\left[\left(\sigma_{q}\right)_{\text {on }}\right]_{\text {Normal }}$} & 10 & $\mathrm{CS} \mathrm{MB}$ & 10,000 & \multirow{2}{*}{$\begin{array}{l}\text { Distance } \\
\text { (ON-QC) }\end{array}$} & \multirow{2}{*}{490} \\
\hline$j \in$ & $\{\mathrm{ON}, \mathrm{QC}, \mathrm{MB}\}$ & {$\left[\left(\sigma_{\mathrm{q}}\right)_{\mathrm{BO}}\right]_{\text {Normal }}$} & 9 & $\mathrm{Ca}$ on & $500 \mathrm{~K}$ & & \\
\hline $\mathrm{R}$ Ontario & 205,875 & {$\left[\left(\sigma_{q}\right)_{M B}\right]_{\text {Normal }}$} & 8 & $\mathrm{Ca} \mathrm{Qc}$ & $500 \mathrm{~K}$ & \multirow{2}{*}{$\begin{array}{l}\text { Distance } \\
\text { (ON-MB) }\end{array}$} & \multirow{2}{*}{1270} \\
\hline$R_{\text {Quebec }}$ & 122,000 & $\mathrm{D}_{\mathrm{ON}} /\left[\left(\mu_{\mathrm{d}}\right)_{\mathrm{ON}}\right]_{\text {Normal }}$ & 135,000 & $\mathrm{Ca} \mathrm{MB}_{\mathrm{B}}$ & $500 \mathrm{~K}$ & & \\
\hline $\mathrm{R}_{\text {Manitoba }}$ & 19,825 & $\mathrm{D}_{\mathrm{oN}} /\left[\left(\mu_{\mathrm{d}}\right)_{\mathrm{QC}}\right]_{\text {Normal }}$ & 80,000 & $\mathrm{P}$ & 250 & \multirow{2}{*}{$\begin{array}{l}\text { Distance } \\
\text { (QC-MB) }\end{array}$} & \multirow{2}{*}{1550} \\
\hline$\left[\left(\mu_{q}\right)_{\text {oN }}\right]_{\text {Normal }}$ & 50 & $\mathrm{D}_{\mathrm{ON}} /\left[\left(\mu_{\mathrm{d}}\right)_{\mathrm{MB}}\right]_{\text {Normal }}$ & 13,000 & $\mathrm{U}$ & 15 & & \\
\hline$\left[\left(\mu_{q}\right)_{\mathrm{Qc}}\right]_{\text {Normal }}$ & 45 & {$\left[\left(\sigma_{d}\right)_{O N}\right]_{\text {Normal }}$} & 1,350 & 0 & 110 & \multirow{5}{*}{$\begin{array}{c}\text { Distance } \\
\text { (ON-ON) } \\
\text { (MB-MB) } \\
\text { (QC-QC) }\end{array}$} & \multirow{5}{*}{ Zero } \\
\hline$\left[\left(\mu_{\mathrm{q}}\right)_{\mathrm{MB}}\right]_{\text {Normal }}$ & 40 & {$\left[\left(\sigma_{\mathrm{d}}\right)_{\mathrm{QC}}\right]_{\text {Normal }}$} & 800 & $\alpha$ & 169 & & \\
\hline$\left[\left(\mu_{\mathrm{q}}\right)_{\mathrm{ON}}\right]_{\text {Expo }}$ & 15 & {$\left[\left(\sigma_{\mathrm{d}}\right)_{\mathrm{MB}}\right]_{\text {Normal }}$} & 130 & $\beta$ & 0.68 & & \\
\hline$\left[\left(\mu_{q}\right)_{\alpha c}\right]_{\text {Expo }}$ & 13 & CS ON & 10,000 & $a$ & 90 & & \\
\hline$\left[\left(\mu_{q}\right)_{M B}\right]_{\text {Expo }}$ & 11 & $\mathrm{Cs} \mathrm{QC}$ & 10,000 & $\mathrm{~b}$ & 0.2 & & \\
\hline
\end{tabular}

Table 1: Numerical Example Parameters

To present the logic in parameters calculation, few examples are given:

- According to (State of North Carolina, Department of Administration, 2011) and (Ontario Tire Stewardship, 2009), the average number of nail holes in an ORT tire is about 20 which is assumed to occur in the middle of the quality spectrum. Also, average cost of retreading a tire is $\$ 135$ and $25 \%$ of it is assumed to be contributed by the repair stage. Thus, 20 repairs are associated with $\$ 34$. As a result, worst possible quality occurs at 40 repairs with a cost of $\alpha=135+34=169$. By applying the slope function $\beta=0.68$.

- According to (Ontario Tire Stewardship, 2009), average cost of purchasing a retreadable tire is $\$ 100$. Thus, it is associated with a tire that has 20 nail holes in it. It is assumed that each tire with no repair needs is purchased by $\$ 110$. Thus, we can workout $a$ to be 90 and $b$ to be 0.2 .

- To avoid model complexity, $U$ and $O$ are calculated based on the total cost associated with the mid quality reading. If a more complex and rigorous method is needed, the reader may refer to Galbreth \& Blackburn (2006). In the paper, $U$ and $O$ are calculated using the average total cost spent on remanufacturing that is dependent on demand and optimal acquired return quantity. Thus,

$U=$ price - total cost of return at mid-quality reading $\left(q_{i}=50\right)$

$$
=250-(90+0.2 * 50)-(169-0.68 * 50)=250-100-135=15
$$

$O=$ total cost of return at mid-quality reading $\left(q_{i}=50\right)-$ salvage value $\left(s=\frac{p}{2}\right)$

$$
=(90+0.2 * 50)+(169-0.68 * 50)-\frac{250}{2}=110
$$

The different costs vs. quality linear relationships are constructed in Figure 2 . The last relationship is the total spending/cost on returns with respect to each quality grade if they are to be accepted into the facility. Such a relationship is formed by adding both the acquisition cost and the remanufacturing cost. Normally, this relationship follows a decreasing pattern. If this relationship follows an increasing pattern, which this model does not support, then the 
facility is better off remanufacturing the worse quality returns rather than the better quality returns.
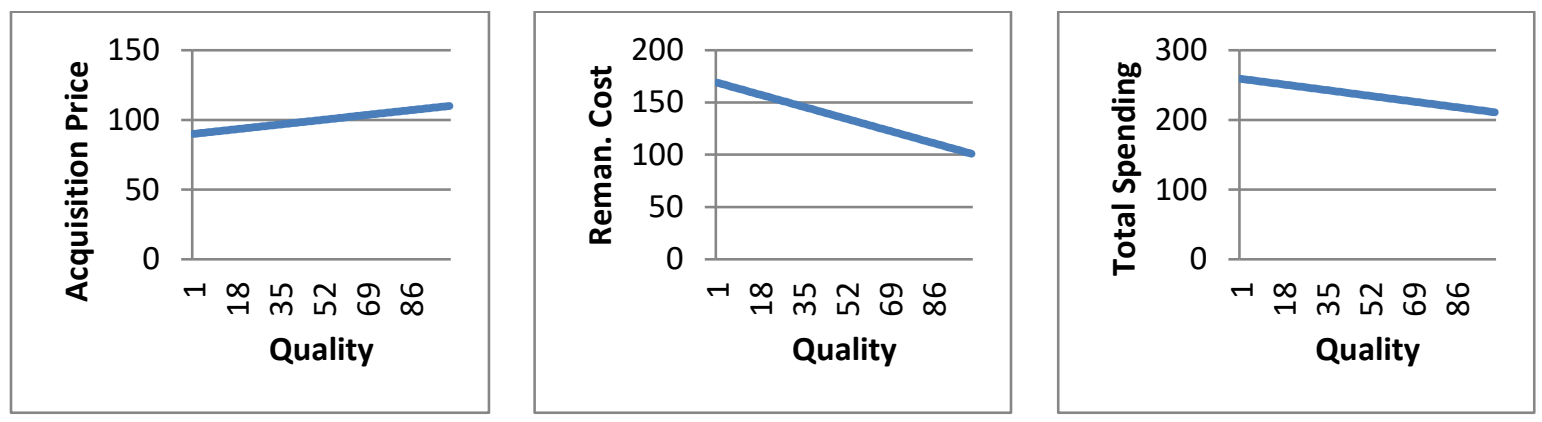

Figure 2: Acquisition Price, Remanufacturing Cost and Total Spending vs. Quality Linear Relationships Constructed for the Numerical Example

The solution for the problem presented above is as the following:

\begin{tabular}{|c|c|c|c|c|c|}
\hline & & $\begin{array}{l}\text { Exponential q } \\
\text { and } \\
\text { Deterministic D }\end{array}$ & $\begin{array}{c}\text { Exponential q } \\
\text { and } \\
\text { Normal D }\end{array}$ & $\begin{array}{l}\text { Normal q } \\
\quad \text { and } \\
\text { Deterministic D }\end{array}$ & $\begin{array}{l}\text { Normal q } \\
\text { and } \\
\text { Normal D }\end{array}$ \\
\hline \multicolumn{2}{|l|}{ Total Profit $\pi$} & $\$ 107,644$ & $\$ 59,733$ & $\$ 3,721,452$ & $\$ 3,603,820$ \\
\hline \multirow{3}{*}{ Optimal Quality } & Qon Factory & 6.3 & 6.6 & 46.0 & 46.3 \\
\hline & QQC Factory & 5.5 & 5.8 & 41.4 & 41.6 \\
\hline & $Q_{\text {MB Factory }}$ & 4.6 & 4.9 & 36.8 & 37.0 \\
\hline \multirow{3}{*}{$\begin{array}{l}\text { Number of Items } \\
\text { Remanufactured by Factory i }\end{array}$} & ON Factory & 135,000 & 132,340 & 135,000 & 133,060 \\
\hline & QC Factory & 80,000 & 78,409 & 80,000 & 78,815 \\
\hline & MB Factory & 13,000 & 12,739 & 13,000 & 12,802 \\
\hline \multirow{9}{*}{$\begin{array}{l}\text { Optimal Number of Items } \\
\text { Delivered by Factory i to } \\
\text { Market } \mathrm{j}-\left(\mathrm{V}_{\mathrm{ij}}\right)\end{array}$} & ON - ON & 135,000 & 132,340 & 135,000 & 133,060 \\
\hline & ON - QC & - & - & - & - \\
\hline & $\mathrm{ON}-\mathrm{MB}$ & - & - & - & - \\
\hline & QC-ON & - & - & - & - \\
\hline & $Q C-Q C$ & 80,000 & 78,409 & 80,000 & 78,815 \\
\hline & $\mathrm{QC}-\mathrm{MB}$ & - & - & - & - \\
\hline & $M B-O N$ & - & - & - & - \\
\hline & $\mathrm{MB}-\mathrm{QC}$ & - & - & - & - \\
\hline & $M B-M B$ & 13,000 & 12,739 & 13,000 & 12,802 \\
\hline \multirow{3}{*}{$\begin{array}{l}\text { Operation of Facility } i\left(\omega_{i}\right) \\
0=\text { facility } i \text { is not operating } \\
1=\text { facility } i \text { is operating }\end{array}$} & ON Factory & 1 & 1 & 1 & 1 \\
\hline & QC Factory & 1 & 1 & 1 & 1 \\
\hline & MB Factory & 1 & 1 & 1 & 1 \\
\hline
\end{tabular}

Table 2: Numerical Example Results

In both deterministic cases, demand is fully satisfied. Intuitively, deterministic demand is satisfied as long as the total spending on remanufacturing is less than the selling price plus the under-stocking cost $(P+U)$. Also, we can notice from the results presented in the tables above that the settings in which quality is distributed normally are more profitable than the settings in 
which quality is distributed exponentially and has higher optimal quality readings. This is due to the fact that the normal distribution has most of its returns under the bell shape centered somewhere around the middle quality, while the exponential distribution has most of its returns accumulated towards the lower qualities. Thus, the enterprise's total spending on remanufacturing is high in the later case. It is found that a system with beta distribution will behave similarly under different shape parameters (Watanabe, Kusuawa \& Arizono 2013). It is, also, important to understand that this superiority could be reversed if the amount of returns is extremely high. This fact is true because each distribution behave differently towards its higher end of quality. Also, we can notice that $O N, Q C$ and $M B$ facilities are all operating and each market's demand is satisfied from its facility's production.

\section{Sensitivity Analysis}

To proceed with the analysis, few parameters have been changed to show certain characteristics in the models.

\subsection{Return Quantity $\left(R_{i}\right)$ vs. Optimal Quality}

Let us assume that we have one facility in ON that satisfies its own market's demand. As shown in Figure 3, when the return quantity increases, the optimal minimum quality increases. It is noticeable that the optimal minimum quality for the normally distributed quality is much higher than what it is for the exponentially distributed quality. Similar to Galbreth and Blackburn (2006), the difference between the stochastic demand and deterministic demand solution is small. However, it is noted that the difference is also sensitive to the parameter setting. For example, if $R_{O N}, D_{O N} / \mu_{d_{O N}}$ and $\sigma_{d_{O N}}$ values are changed to 200, 100 and 30, respectively, then the optimal quality in the deterministic case is $50 \%$ and in the stochastic case is $55.4 \%$.

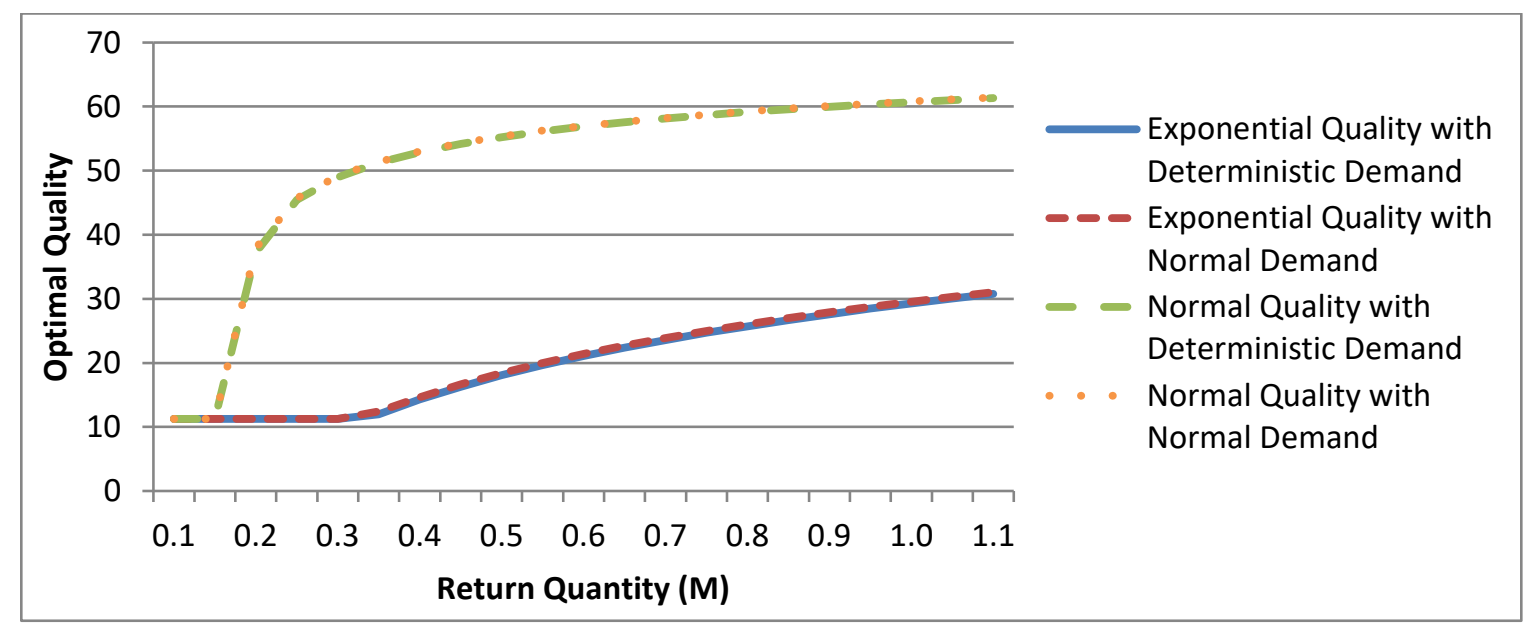

Figure 3: Optimal Quality vs. Return Quantity 


\subsection{Total Spending Relationship vs. Optimal Quality}

$a, \alpha, b$ and $\beta$ work in synchronization to set the total spending on each quality graded return. The term $(a+\alpha)$ sets the total spending at the lowest quality level, while the term $(b-\beta)$ sets the rate of reduction in total spending as quality improves. If $(a+\alpha)$ is lower than the selling price $P$, then the optimal quality is used to set the acquisition quantity with which demand is satisfied, and the expected under-stocking and over-stocking costs are minimized. If $(a+\alpha)$ is higher than the selling price $P$, then there will be returns that will generate a loss if remanufactured. If those returns are needed to satisfy demand, then the optimal quality is used to weigh the loss of incurring under-stocking cost vs. the loss of remanufacturing. Once the later loss is higher, the optimal quality will increase in an effort to only incur under-stocking cost. This behavior has happened when the $b$ value increased from 0.1 to 0.9 resulting in a decrease in the slope of the total spending vs. quality relationship and, thus, an increase in remanufacturing cost for those returns with higher quality (Figure 4). Note that a higher value of $b$ could represents higher incentives needed to acquire returns with higher quality. In addition, we can notice that the exponential models get affected first, because they offer lower number of high quality returns. Intuitively, to make profit with all sold items, the facility should try to increase the amount of returns $\left(R_{i}\right)$ until the optimal quality is more than the quality associated with $P$.

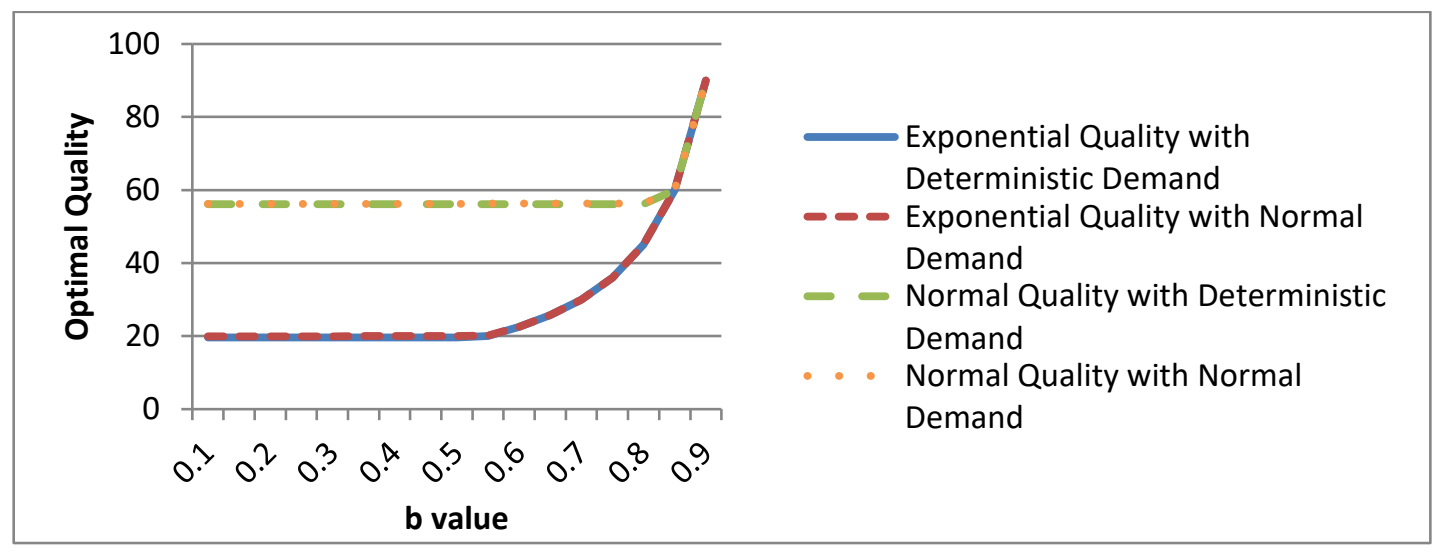

Figure 4: Optimal Quality vs. b Value

Relatively, in a hybrid system the optimal minimum quality is used to weigh the loss associated with remanufacturing vs. the loss associated with manufacturing new items (Watanabe, Kusuawa \& Arizono 2013). This is related to the "regret loss" which is identified by Robotis, Boyaci \& Veter (2012) as the increment of remanufacturing cost over manufacturing cost for a certain quality. 


\subsection{Quality Uncertainty $\left(\sigma_{q_{i}}\right)$ vs. Optimal Quality and Profit}

When quality is normally distributed and the uncertainty decreases, the bell shape of the quality distribution shrinks. Such a process deprives the system from having higher quality returns originally located at the higher end of the quality spectrum. As a result, the profit declines and the total spending increases in the system due to the need of remanufacturing lower quality returns (see Figure 5). Also, as quality uncertainty decreases the optimal minimum quality will change (increase/decrease) accordingly to preserve the acquisition quantity that will, only, satisfy demand needed to minimize all costs (see Figure 6 and Figure 7). In a related topic, Galbreth and Blackburn (2010) argue that if $R_{i}$ is a decision variable, then as quality uncertainty decreases $R_{i}$ will increase and the profit will change (increase/decrease) accordingly. This change in profit is minimal when $R_{i}^{*}$ is low.

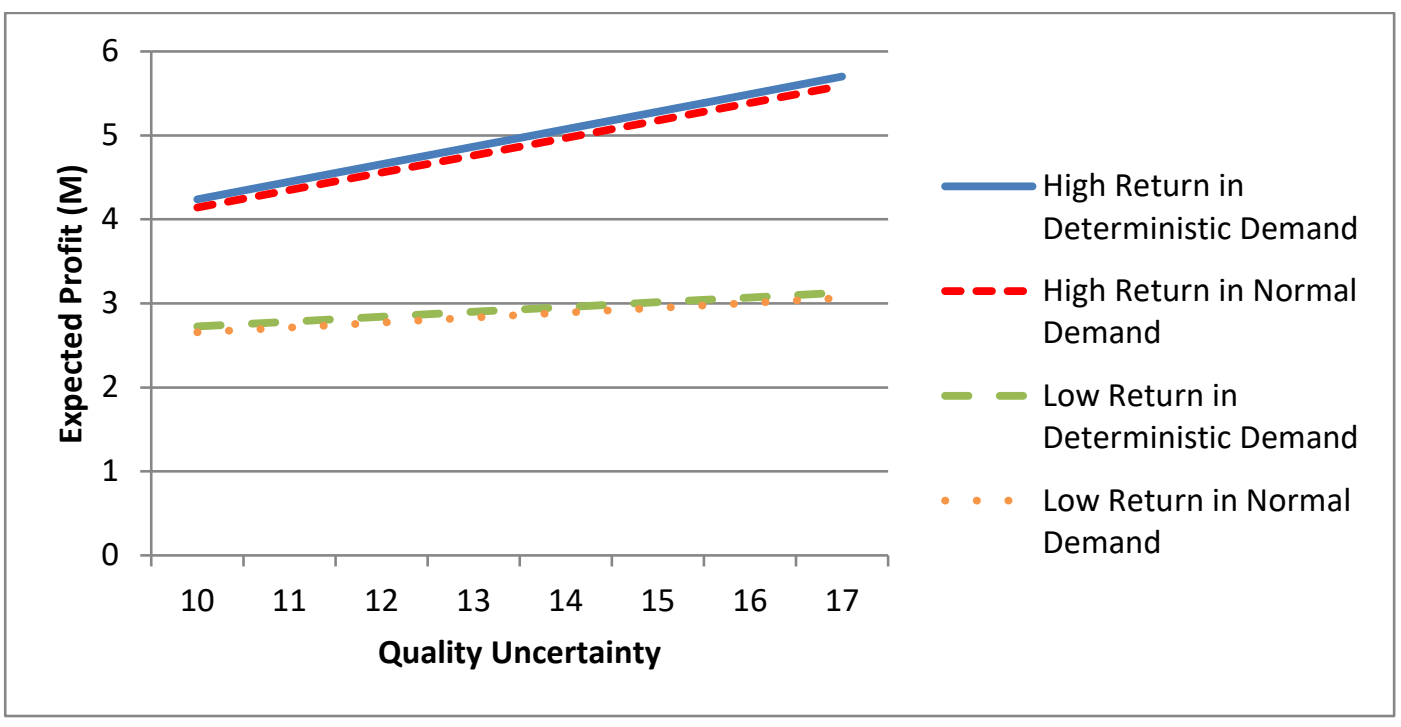

Figure 5: Expected Profit vs. Quality Uncertainty

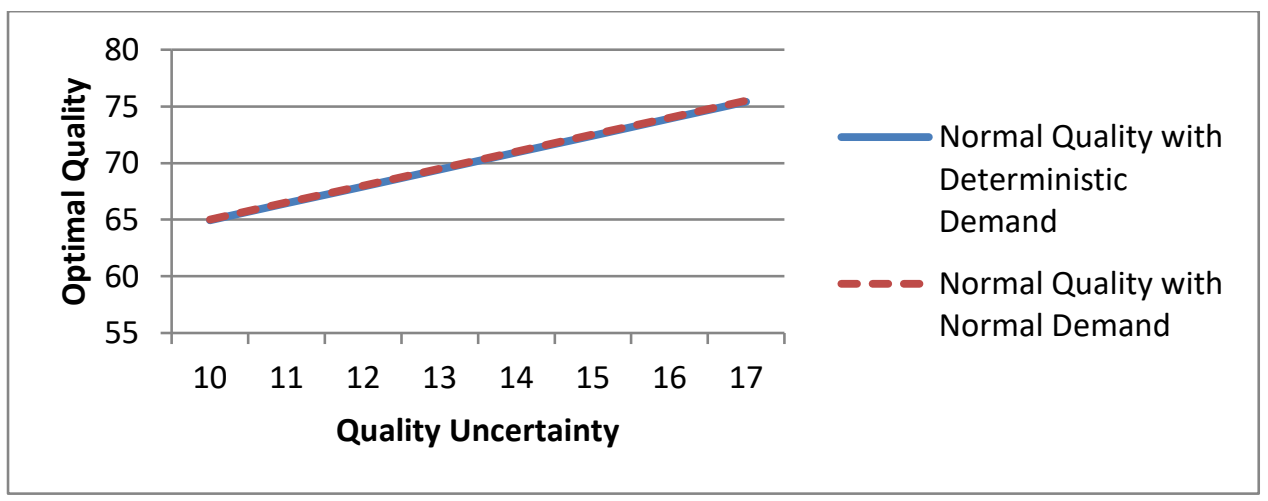

Figure 6: Optimal Quality vs. Quality Uncertainty When Return Quantity is High 


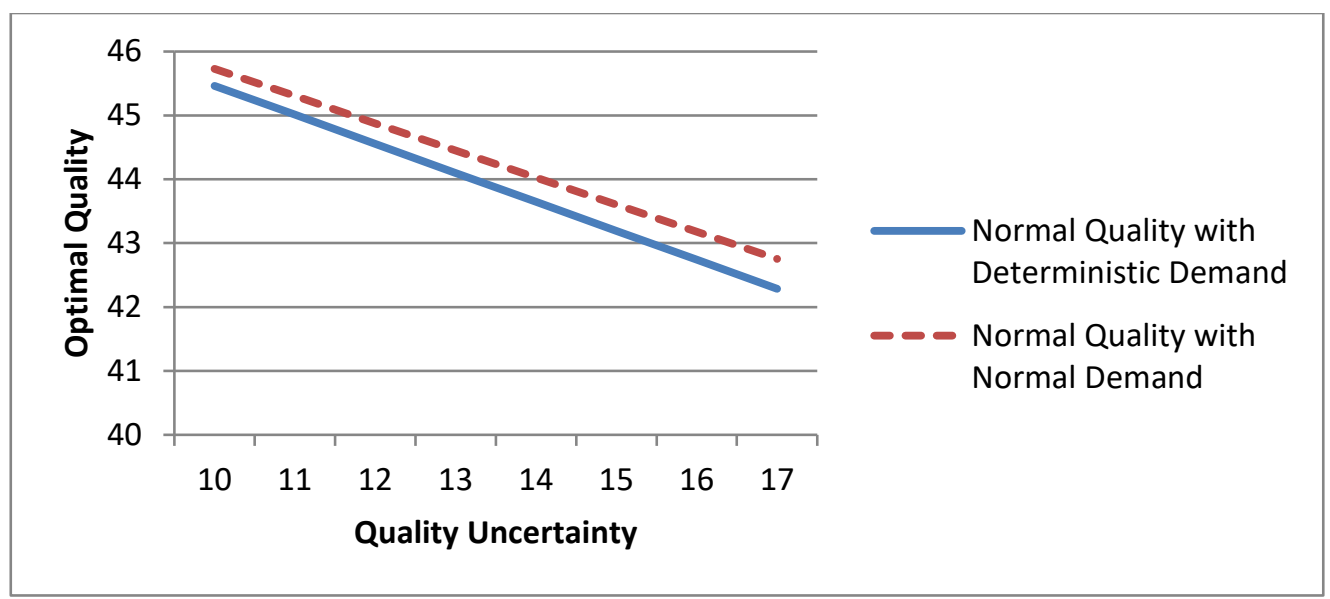

Figure 7: Optimal Quality vs. Quality Uncertainty When Return Quantity is Low

\subsection{Demand Uncertainty $\left(\sigma_{d_{j}}\right)$ vs. Optimal Quality and Profit}

In the normally distributed demand cases, as uncertainty increases the system's expected profit decreases. This is due to the fact that the increase in demand uncertainty increases the chance of experiencing more over-stocking $(O)$ and under-stocking $(U)$ costs.

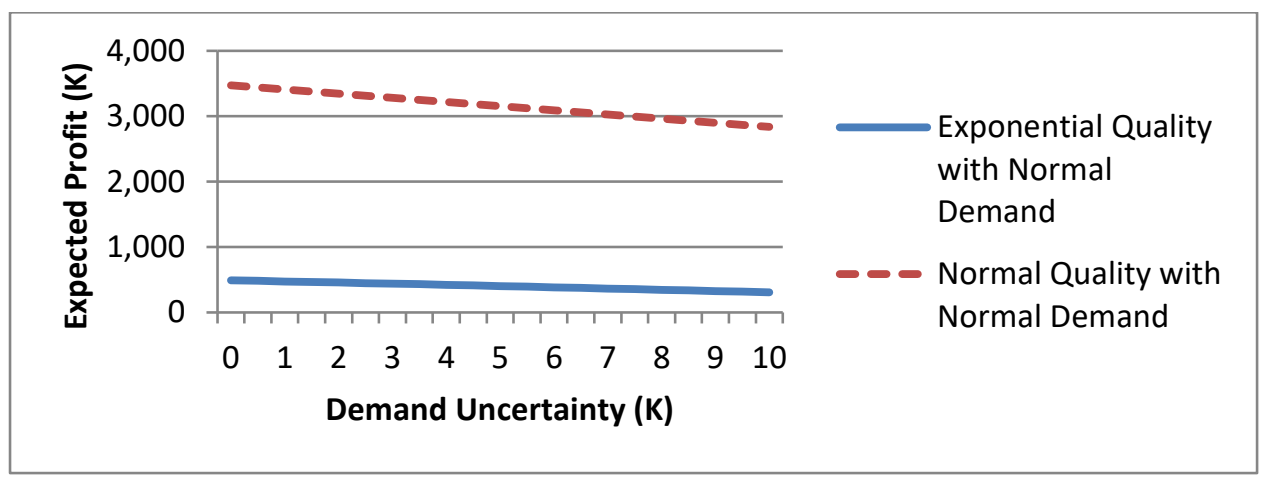

Figure 8: Expected Profit vs. Demand Uncertainty

Since $O \gg U$, then as the demand uncertainty increases, the optimal quality increases to reduce the acquisition quantity and, thus, reduce the increasing chance of bearing high overstocking cost (see Figure 9). This increase in the optimal quality is encouraged by the fact that there is an associated decrease in the total spending. Beside the increase in the optimal minimum quality level, Teunter \& Flapper (2011) argue that the optimal amount of returns $R_{i}^{*}$ should, also, increase with the increase in demand uncertainty if $R_{i}$ is a decision variable. 


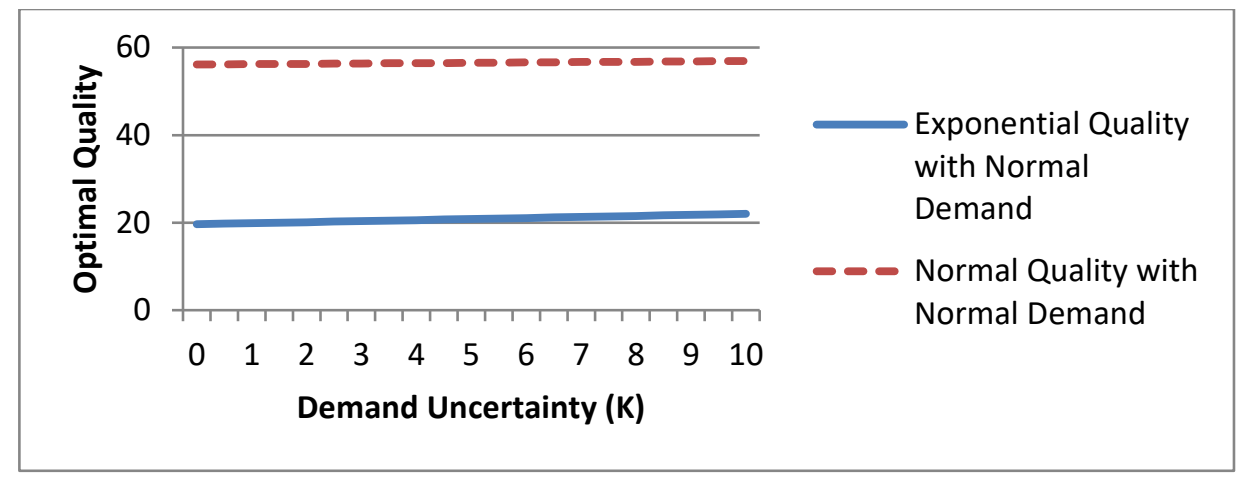

Figure 9: Optimal Quality vs. Demand Uncertainty

If it happens that $U \gg O$, then there is a trade-off between decreasing the optimal quality to avoid the increasing chance of bearing high under-stocking cost and the high cost associated with remanufacturing lower quality returns. Thus, depending on the total spending vs. quality linear relationship and the difference between $U$ and $O$, the models could either decrease or increase the optimal quality as demand uncertainty increases.

\subsection{Transportation Cost vs. Facility Production, Optimal Quality and Profit}

If the enterprise runs many facilities, then the total profit could be increased by managing critical trade-offs between three different costs. First, is cost of transportation. The higher the transportation cost, the higher the need for more facilities to satisfy different markets' demand. Second, is total spending associated with remanufacturing returns. The more facilities are utilized or opened for remanufacturing purposes, the less the total spending would be. This is due to the fact that with more facilities, the enterprise is able to utilize more high quality returns from all markets. Third, is setup cost. High facility setup costs are always associated with the need to aggregate production. In this Analysis, we use the model with normal quality and deterministic demand setting.

To conduct the analysis, transportation cost per mile per tire is increased from $0.1 \mathrm{c}$ to $2 \mathrm{c}$. At the higher transportation costs, the enterprise has nothing but to supply each market's demand from its own facility (see Figure 10).

As the transportation cost declines below 1.8c, we can notice that ON's production increases, while QC's production decreases. This could be achieved by decreasing ON's and increasing $Q C^{\prime}$ 's optimal qualities respectively (see Figure 11). Notice that $\left(\mu_{q}\right)_{O N}=50$ and $\left(\mu_{q}\right)_{C Q}=40$. Thus, if $R_{O N}$ is very high, then ON's facility may possess extra high quality returns that could be cheaply remanufactured and transported to QC. At this stage, the cost associated with remanufacturing ON's high quality returns is not low enough to overcome the high transportation cost between $\mathrm{ON}$ and $\mathrm{MB}$. 
When the transportation cost is, as low as, $1.2 C$ and below, ON's facility supply portion of $Q C^{\prime} s$ and $M B^{\prime}$ 's demands. By further decreasing transportation cost to $0.9 \zeta$, the enterprise can shut down MB's facility and satisfy all of its demand from ON's facility, because $(d)_{M B},(R)_{M B}$ and $\left(\mu_{q}\right)_{M B}$ values are low. From Figure 12, we can notice the great change in the enterprise profitability as a result of this shut down.

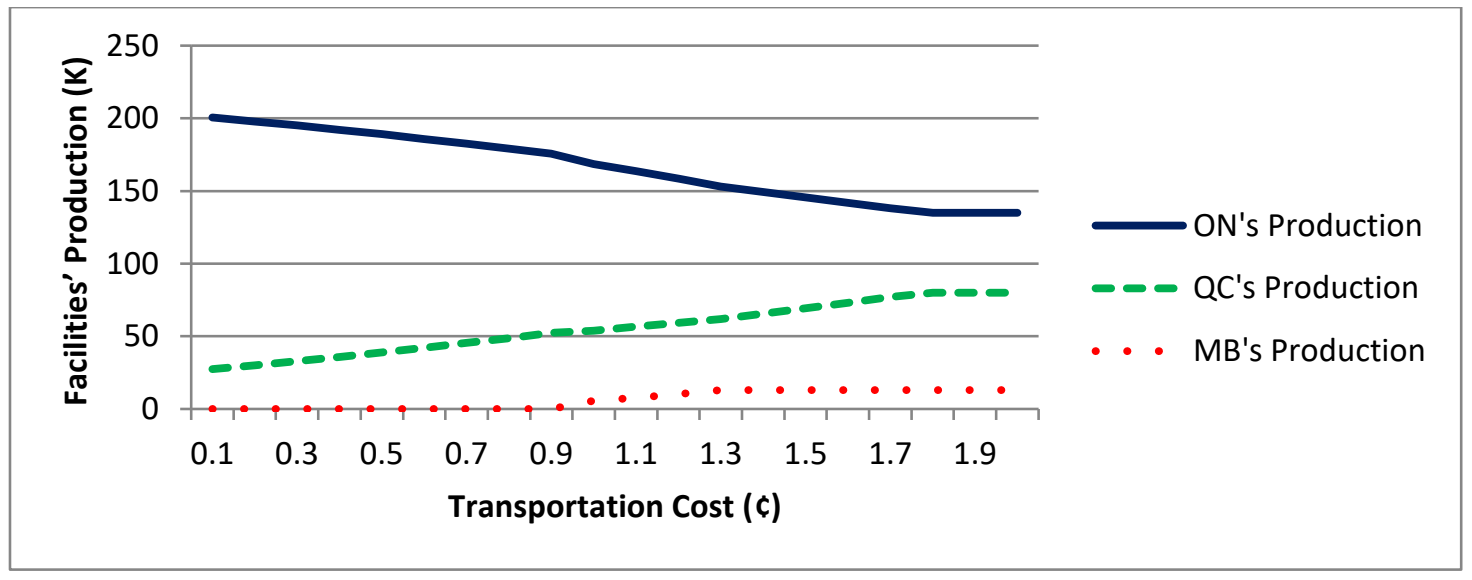

Figure 10: Facilities' Production vs. Transportation Cost

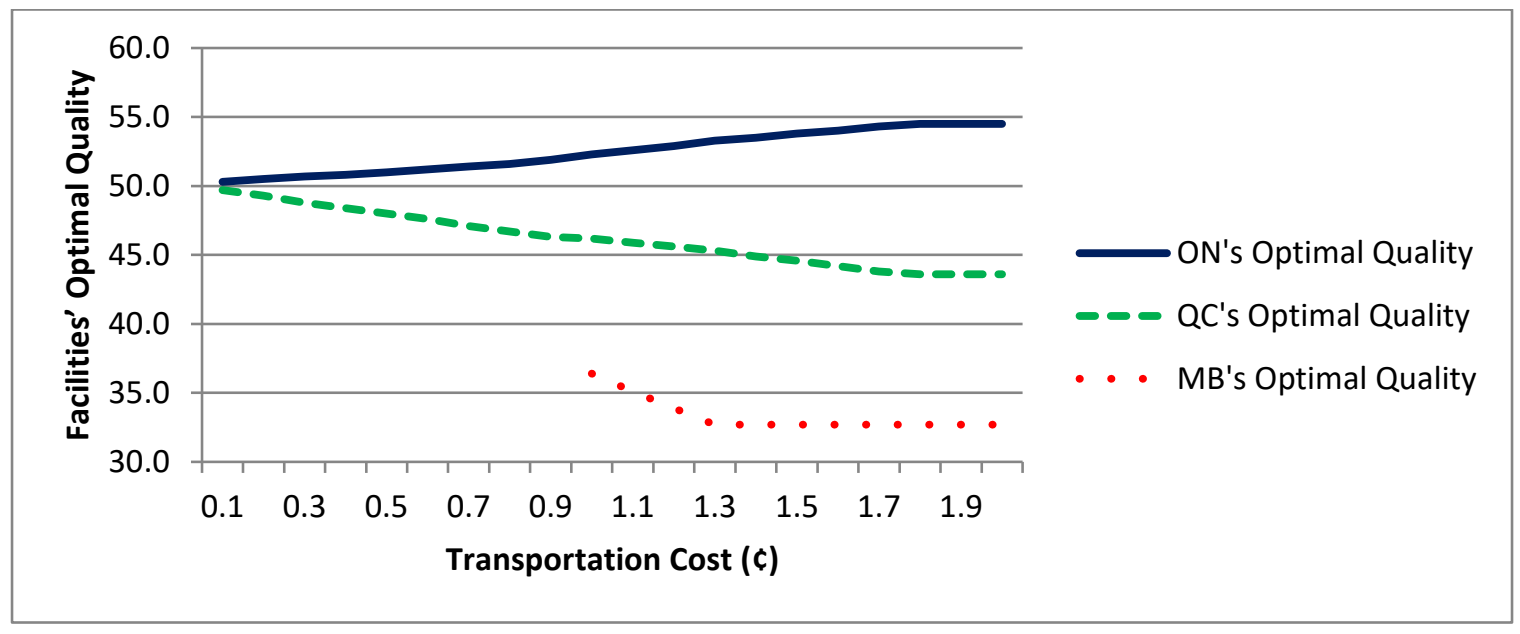

Figure 11: Facilities' Optimal Quality vs. Transportation cost 


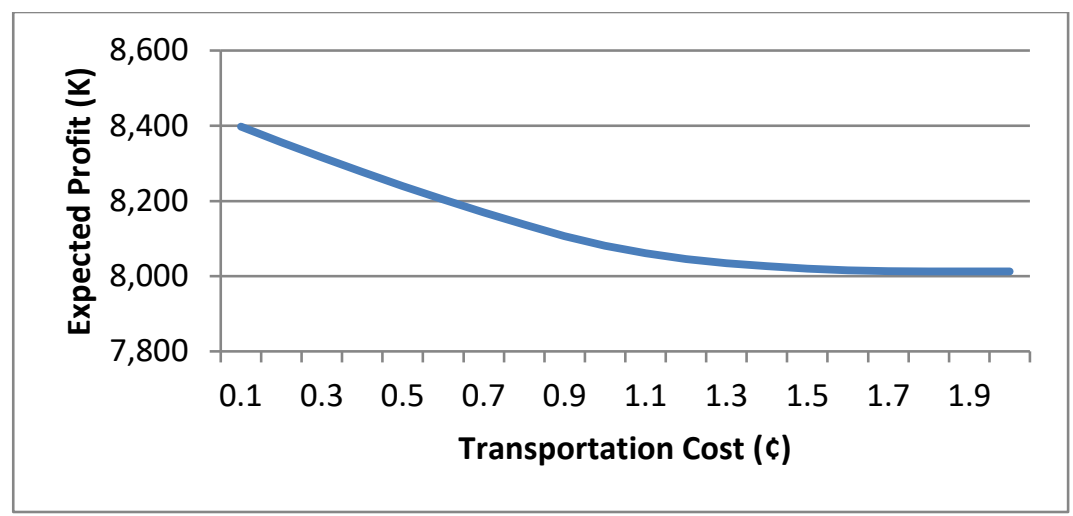

Figure 12: Expected Profit vs. Transportation Cost

\section{Extension of the Model with Return Quantity Decision}

In this section we extend the problem to determine both optimal minimum acceptable return quality $\left(Q_{i}\right)$ and return quantity $\left(R_{i}\right)$ simultaneously. The return quantity is introduced as a decision variable and the inspection cost $(T)$ is introduced as a parameter. Thus, the problem modeling will change as the following:

Deterministic demand case (Model 3):

$\operatorname{Max} \pi-\sum_{i=1}^{F} R_{i} * T$

Subject to:

Constraint (2) - (7) and $R_{i} \geq 0$

Stochastic demand case (Model 4):

$\operatorname{Max} \pi^{\prime}-\sum_{i=1}^{F} R_{i} * T$

Subject to:

Constraint (2), (3), (5), (7) and $R_{i} \geq 0$

A single facility and single market setting is used to test the problem and the solution is found through GAMS. The parameters used in this section are those assigned for ON in Table 1, and the inspection cost per tire is ranged from $\$ 1$ to $\$ 5$. In the tables below, we study system's performance under Model 4 where $Q_{i}$ and $R_{i}$ are decision variables, and compare that to system's performance under Model 2 where $Q_{i}$ is a decision variable and $R_{i}$ is a parameter. To have a valid comparison, total inspection cost $\left(\sum_{i=1}^{F} R_{i} * T\right)$ should also be subtracted from the expected profit functions $\left(\pi^{\prime}\right)$ in equations (8). Tables 3 and 4 report the solutions for both exponential and normal quality distributions respectively, where the values of the profit for Model 2 are relative decrease (in percentage) compared to the profit of Model 4. 


\begin{tabular}{|c|c|c|c|c|c|c|}
\hline \multicolumn{2}{|c|}{ Inspection Cost } & 1 & 2 & 3 & 4 & 5 \\
\hline \multirow{3}{*}{ Model 4} & $Q^{*}$ & 29.6 & 19.2 & 13.1 & 8.8 & 5.5 \\
\hline & $R^{*}$ & 957390 & 478150 & 318530 & 238750 & 190900 \\
\hline & $\pi^{*}$ & 1977700 & 1314500 & 926870 & 652050 & 439000 \\
\hline \multirow{2}{*}{$\begin{array}{c}\text { Model } 2 \text { with } \\
\mathrm{R}=1.1 R^{*}\end{array}$} & $Q^{*}$ & 31.0 & 20.6 & 14.6 & 10.2 & 6.9 \\
\hline & $\pi^{*}(\%$ of the decrease) & 0.228 & 0.342 & 0.483 & 0.686 & 1.018 \\
\hline \multirow{2}{*}{$\begin{array}{c}\text { Model } 2 \text { with } \\
\mathrm{R}=1.3 R^{*}\end{array}$} & $Q^{*}$ & 33.5 & 23.1 & 17 & 12.7 & 9.4 \\
\hline & $\pi^{*}$ (\% of the decrease) & 1.820 & 2.739 & 3.874 & 5.503 & 8.166 \\
\hline \multirow{2}{*}{$\begin{array}{c}\text { Model } 2 \text { with } \\
\mathrm{R}=0.9 R^{*}\end{array}$} & $Q^{*}$ & 28 & 17.6 & 11.6 & 7.2 & 3.9 \\
\hline & $\pi^{*}$ (\% of the decrease) & 0.258 & 0.388 & 0.551 & 0.784 & 1.162 \\
\hline \multirow{2}{*}{$\begin{array}{c}\text { Model } 2 \text { with } \\
\mathrm{R}=0.7 R^{*}\end{array}$} & $Q^{*}$ & 24.3 & 13.9 & 7.8 & 3.5 & 0.1 \\
\hline & $\pi^{*}$ (\% of the decrease) & 2.736 & 4.116 & 5.829 & 8.279 & 12.287 \\
\hline
\end{tabular}

Table 3: Comparing system's performance under Model 2 and Model 4 when quality is exponentially distributed

\begin{tabular}{|c|c|c|c|c|c|c|}
\hline \multicolumn{2}{|c|}{ Inspection Cost } & 1 & 2 & 3 & 4 & 5 \\
\hline \multirow{3}{*}{ Model 4} & $Q^{*}$ & 54.7 & 49.7 & 46.1 & 43.1 & 40.4 \\
\hline & $R^{*}$ & 415860 & 259180 & 204130 & 176550 & 160560 \\
\hline & $\pi^{*}$ & 3578600 & 3257900 & 3029900 & 2840900 & 2673000 \\
\hline \multirow{2}{*}{$\begin{array}{c}\text { Model } 2 \text { with } \\
\mathrm{R}=1.1 R^{*}\end{array}$} & $Q^{*}$ & 55.5 & 50.8 & 47.6 & 45.2 & 43.1 \\
\hline & $\pi^{*}$ (\% of the decrease) & 0.075 & 0.114 & 0.168 & 0.236 & 0.325 \\
\hline \multirow{2}{*}{$\begin{array}{c}\text { Model } 2 \text { with } \\
\mathrm{R}=1.3 R^{*}\end{array}$} & $Q^{*}$ & 56.9 & 52.7 & 50 & 48 & 46.5 \\
\hline & $\pi^{*}$ (\% of the decrease) & 0.576 & 0.878 & 1.241 & 1.693 & 2.278 \\
\hline \multirow{2}{*}{$\begin{array}{c}\text { Model } 2 \text { with } \\
\mathrm{R}=0.9 R^{*}\end{array}$} & $Q^{*}$ & 53.7 & 48.2 & 44 & 40.2 & 35.9 \\
\hline & $\pi^{*}$ (\% of the decrease) & 0.089 & 0.141 & 0.215 & 0.320 & 0.501 \\
\hline \multirow{2}{*}{$\begin{array}{c}\text { Model } 2 \text { with } \\
\mathrm{R}=0.7 R^{*}\end{array}$} & $Q^{*}$ & 51.1 & 43.8 & 35.2 & 0 & 0 \\
\hline & $\pi^{*}$ (\% of the decrease) & 0.984 & 1.679 & 2.901 & 13.017 & 24.736 \\
\hline
\end{tabular}

Table 4: Comparing system's performance under Model 2 and Model 4 when quality is normally distributed

Considering the case of normally distributed quality presented in Table 4, when Model 4 is used and the inspection cost increases from $\$ 1$ to $\$ 5$, the optimal minimum quality, optimal return quantity and expected profit drop $26.14 \%, 61.39 \%$ and $25.31 \%$ respectively. Such a high drop in profitability should encourage retreading plants to revise their process of inspecting returns. For example, replacing human powered inspection machines by fully automatic ones could drastically increase profitability of the system even if they are tied up to higher investment costs. With such change the facility could add up more inspection capacity and reduce inspection cost per tire $(T)$. Also, If Model 2 is used and the amount of returns is increased or decreased by $10 \%,-10 \%, 30 \%,-30 \%$ in comparison to $R^{*}$, then the average drop in profitability through all inspection costs will be $0.167 \%, 0.227 \%, 1.228 \%$ and $7.179 \%$ respectively. Similar to Galbreth \& Blackburn (2010), there is a trade-off between the total inspection cost and the total spending on remanufacturing. In our work, this trade-off is controlled by the amount of returns and the optimal minimum quality accepted for remanufacturing. In contrast to Galbreth \& Blackburn (2010), our work gives a precise reading for the optimal quality that enables remanufacturers to efficiently accept or reject a return directly after the inspection is conducted. 


\section{Conclusions and Managerial Insights}

The quality of returned products plays a crucial role in the development of remanufacturing network. This work develops MINLP models to simultaneously determine the optimal configuration of remanufacturing networks and return quality decision under return quality and demand uncertainties. An extension is given in Section 6 where the amount of returns is also considered as a decision variable.

If the remanufacturing enterprise has the advantage of inspecting cores before purchasing, then it is important to use the optimal minimum quality as a major acceptance threshold in any return accepting/rejecting decision. Such a strategy saves the enterprise the costs of acquiring and disposing off unwanted returns. Also, the remanufacturing enterprise should deal with the increase in the amount of returns as an opportunity to enhance profit rather than unnecessary exerted effort especially with lower inspection costs. Similar to Galbreth \& Blackburn (2006), the higher the amount of returns, the more quality selective the facility could be and, thus, the more profit it could generate. Compared to Robotis, Boyaci \& Veter (2012) who view quality uncertainty as an opportunity to invest, this work suggests that quality uncertainty should be viewed is a chance to reduce remanufacturing cost rather than an unwelcomed interruption.

If an enterprise runs multiple facilities, then managing transportation cost, setup cost and total spending effectively is vital to reach the system's optimal performance. For example, an optimal solution may lead a market to be supplied by both a local facility and a remote facility due to the scarcity of high quality returns in the local facility. Therefore, decentralized/centralized decision is not only dependent on transportation cost, but also dependent on return quality and setup cost. Our model and solution approach provide an effective tool to make those decisions.

Also, remanufacturing system's behavior and profitability depends greatly on the distribution of returns along the quality spectrum. Generally, the more returns lie toward the higher end of quality, the more profitable the remanufacturing system is. Thus, if a remanufacturing facility is not facing extremely high returns, then a quality distributed normally is more appealing than a quality distributed exponentially. Relatively, a remanufacturing system facing exponential distribution might have limited chances of success when investing in a design used to increase reusability or amount of returns (Robotis, Boyaci \& Veter 2012). Thus, contracting several geographically distanced collectors to supply a facility with returns might increase returns' quality and, thus, profitability of the system.

Return quantity in our models is assumed to be a parameter or a decision variable. Therefore, a possible extension of this work is to consider return quantity to be stochastic. Also, under-stocking and over-stocking costs should be quality dependent when applied in a 
remanufacturing context. Finally, a future study could model a system with more quality dependent variables such as pre-remanufacturing inventory cost and remanufacturing leadtime. 


\section{REFERENCES}

1. Akcali, E., \& Cetinkaya, S., 2011. Quantitative models for inventory and production planning in closed-loop supply chains. International Journal of Production Research, 49(8), 23732407.

2. Aras, N., Boyaci, T., \& Verter, V., 2004. The effect of categorizing returned products in remanufacturing. IIE Transactions, 36(4), 319-331.

3. Bakal, I. S., \& Akcali, E., 2006. Effects of Random Yield in Remanufacturing with PriceSensitive Supply and Demand. Production and Operation Management, 15(3), 407 - 420.

4. Behret, H., \& Korugan, A., 2009. Performance analysis of a hybrid system under quality impact of returns. Computers \& Industrial Engineering, 56(2), 507-520.

5. Bostel, N., \& Lu, Z., 2007. A Facility Location Model for Logistics Systems Including Reverse Flows: the Case of Remanufacturing Activities. Computers \& Operation Research, 34(2), 299-323.

6. Chiu, Y., Li, M. Y., \& Wang, S. J., 2009. Economic Order Quantity Model in Reverse Logistics that Considers Lead Time, Stochastic Demand and Returned Quantity. Asia Pacific Industrial Engineering and Management Society.

7. El Saadanya, A. M., \& Jaber, M. Y., 2010. A production/remanufacturing inventory model with price and quality dependant return rate. Computers \& Industrial Engineering, 58(3), 352-362.

8. Ferguson, M., Guide Jr., V. D., Koca, E., \& Souza, G. C., 2009. The Value of Quality Grading in Remanufacturing. Production and Operations Management, 18(3), 300-314.

9. Galbreth, M. R., \& Blackburn, J. D., 2006. Optimal Acquisition and Sorting Policies for Remanufacturing. Production and Operations Management, 15(3), 384-392.

10. Galbreth, M. R., \& Blackburn, J. D., 2010. Optimal Acquisition Quantities in Remanufacturing with Condition Uncertainty. Production and Operations Management, 19(1), 61-69.

11. Hsueh, C. F., 2010. Inventory Control for Stochastic Reverse Logistics with Product's Life Cycle. Proceedings of the World Congress on Engineering , 3.

12. Inderfurth, K., 2005. Impact of uncertainties on recovery behavior in a remanufacturing environment. International Journal of Physical Distribution \& Logistics Management, 35(5), 318-336. 
13. Jayaraman, V., Guide Jr., V.D.R., \& Srivastava R., 1999. A Closed-Loop Logistic Model for Remanufacturing. The Journal of Operational Research Society, 50(5), 497-508.

14. Kim, K., Song, I., Kim, J., \& Jeong, B., 2006. Supply planning model for remanufacturing system in reverse logistics environment. Computers \& Industrial Engineering, 51(2), 279287.

15. Ko, H. J., \& Evans G. W., 2007. Genetic Algorithm-Based Heuristic for The Dynamic Integrated Forward/Reverse Logistics Network for 3PL. Computer \& Operation Research, $34(2), 346-366$.

16. Koh, S. G., Hwang, H., Sohn, K. I., \& Ko, C. S., 2002. An Optimal Ordering and Recovery Policy for reusable items. Computers \& Industrial Engineering, 43(1-2), 59-73.

17. Konstantaras, I., Skouri, K., \& Jaber, M. Y., 2010. Lot sizing for a recoverable product with inspection and sorting. Computers \& Industrial Engineering, 58(3), 452-462.

18. Lee, D. H., Dong, M., 2008. A Heuristic to Logistics Network Design for End-of-Life Computer Products Recovery. Transportation Research Part E, 44(3), 455-474.

19. Listes, O., 2007. A Generic Stochastic Model for Supply-and-Return Network Design. Computer \& Operations Research, 34(2), 417-442.

20. Mukhopadhyaya, S. K., \& Ma, H., 2009. Joint procurement and production decisions in remanufacturing under quality and demand uncertainty. International Journal of Production Economics, 120(1), 5-17.

21. Nenes, G., Panagiotidou, S., \& Dekker, R., 2010. Inventory control policies for inspection and remanufacturing of returns: A case study. International Journal of Production Economics, 125(2), 300-312.

22. Ontario Tire Stewardship., 2004. Scrap Tire Diversion Program Plan.

23. Ontario Tire Stewardship., 2009. Used Tires Program Plans.

24. Robotis, A., Bhattacharya, S., \& Van Wassenhove, L. N., 2005. The effect of remanufacturing on procurement decisions for resellers in secondary markets. European Journal of Operational Research, 163(3), 688-705.

25. Robotis A., Boyaci T., \& Veter V., 2012. Investing in reusability of products of uncertain remanufacturing cost: the role of inspection capabilities. International Journal of Production Economics, 140(1), 385-395 
26. Salema, M. I. G., Barbosa-Povoa, A. P., \& Novais, A. Q., 2006. A Warehouse-Based Design Model for Reverse Logistics. Journal of the Operational Research Society, 57(6), 615-629.

27. Salema, M. I. G., Barbosa-Povoa, A. P., \& Novais, A. Q., 2007. An Optimization Model for the Design of a Capacitated Multi-Product Reverse Logistics Network with Uncertainty. European Journal of Operational Research, 179(3), 1063-1077.

28. Saman, H. A., \& Zhang, G., 2012. An Integrated Model for Closed-Loop Supply Chain Configuration and Supplier Selection: Multi-Objective Approach. Expert Systems with Applications, 39(8), 6782-6791.

29. Seitz, M. A., 2007. A critical assessment of motives for product recovery: the case of engine remanufacturing. Journal of Cleaner Production, 15(11-12), 1147-1157.

30. Shi, J., Zhang, G., \& Sha, J., 2011a. Optimal production and pricing policy for a closed loop system. Resources, Conservation and Recycling, 55(6), 639-647.

31. Shi, J., Zhang, G., \& Sha, J., 2011b. Optimal production planning for a multi-product closed loop system with uncertain demand and return. Computers \& Operations Research, 38(3), 641-650.

32. Shi, J., Zhang, G., Sha, J., \& Amin, H. S., 2010. Coordinating production and recycling decisions with stochastic demand and return. Journal of Systems Science and Systems Engineering, 19(4), 385-407.

33. Teunter, R. H., \& Flapper, S. D., 2011. Optimal core acquisition and remanufacturing policies under uncertain core quality fractions. European Journal of Operational Research, 210(2), 241-248.

34. Wassenhove, L. N., \& Zikopoulos, C., 2010. On the effect of quality overestimation in remanufacturing. International Journal of Production Research, 48(18), 5263-5280.

35. Watanabe T., Kusuawa E., \& Arizono I., 2013. Optimal operation for green supply chain in consideration of collection incentive and quality for recycling of used products. Industrial Engineering \& Management Science, 12(4), 2234-6473.

36. Wei, S., Tang O., \& Liu W., 2014. Refund policies for cores with quality variation in OEM remanufacturing. International Journal of Production Economics, http://dx.doi.org/10.1016/j.ijpe.2014.12.006.

37. Zikopoulos, C., \& Tagaras, G., 2008. On the attractiveness of sorting before disassembly in remanufacturing. IIE Transactions, 40(3), 313-323. 